Journal of Advanced Research in Fluid Mechanics and Thermal Sciences

Journal homepage: www.akademiabaru.com/arfmts.html ISSN: 2289-7879

\title{
Predicting Energy Requirement for Cooling and Heating the Building Located in South West of Algeria (Bechar)
}

\author{
Salima Laoufi ${ }^{1,}{ }^{*}$, Belkacem Draoui ${ }^{1}$, Bachir Imine $^{2}$ \\ Energarid Laboratory, University of Tahri Mohamed, Bechar, Algeria \\ 2 Department of Mechanical Engineering, University of Science and Technology, Oran, Algeria
}

\section{ARTICLE INFO ABSTRACT}

\section{Article history:}

Received 14 February 2020 Received in revised form 20 April 2020

Accepted 21 April 2020

Available online 20 September 2020

Keywords:

Building; Cooling; Heating; Temperature; Trnsys

\begin{abstract}
In buildings, many factors influence the energy performance, such as ambient weather conditions, building structure and characteristics, lighting, equipment, occupants and their behavior. This makes the situation complex to accurately predict the building energy consumption and its behavior. The objective of this piece of work is to contribute to the improvement of the energy efficiency of the residential buildings located in Algeria's southern west city of Bechar. In this study, we are trying to calculate the energy consumption for both cooling and heating in Bechar house. The simulation was conducted using TRNSYS program within one year through two different scenarios. The results obtained, revealed that the cooling load reached 12.223,30 KWh per year when the internal loads has been taken into account, the energy requirements for cooling the building present almost $69.51 \%$ of the total needs and the demand for heating presents $30.49 \%$ per year.
\end{abstract}

Copyright @ 2020 PENERBIT AKADEMIA BARU - All rights reserved

\section{Introduction}

Reducing energy costs and increasing the conditions of comfort today is an absolute priority around the world. This can be achieved through the use of ecological means and both cooling and heating loads reduction.

The consumption of energy in the domestic sector in Algeria was probably multiplied by five during the period from 1980 to 2012. Electricity, the natural energy, gas, fuel, coal, wood and even batteries are the vectors of the domestic sector. Moreover, according to the Mediterranean Observatory of Energy reference projections that this tendency will continue intel 2025.

In Algeria the building sector is responsible for nearly $40 \%$ of the total energy consumption, and represents an annual growth rate estimated at $6.28 \%$, Moreover, about $50 \%$ of the total energy consumption in a general building is dissipated through its envelope [1].

\footnotetext{
* Corresponding author.

E-mail address: laoufisalima@gmail.com
}

https://doi.org/10.37934/arfmts.75.3.1324 
The Algerian south, taking in consideration the climate aridity, the buildings are responsible for more than $70 \%$ of electricity consumption in summer period by installing an electric air-conditioning in each room to ensure the comfort [2]. Consequently, preservation of the energy of heating and cooling represents a major target for the residential sector [3].

Mathematical methods have recently been developed to calculate the building cooling and heating loads under local weather conditions in different zones.

Hu et al., [4] develop and modeling of cooling load for a large building with ice-storage systems in Beijing, China. The models describe the dynamics of cooling load, outdoor climate parameters and indoor parameters as one multi-variable nonlinear system in a way that is useful for prediction analysis, the analysis shows that this model is suitable for the practical engineering application and can provide a basis for optimal operation of air conditioning control systems of large public buildings.

Catalina et al., [5] identified the cooling load temperature difference (CLTD) values for flat roofs and walls of buildings for different climatic zones in Mexico, and different construction materials that typically used in Mexico, using the complex finite Fourier transform to solve the one-dimensional transient heat transfer model. The results showed that the average difference between ASHRAEderived values and the obtained CLTD values was $10^{\circ} \mathrm{C}$.

Chenqiu et al., [6] explore the capacity for heating/cooling flexibility in residential buildings in the hot summer and cold winter zone in China, the results showed that the measured indoor temperatures were linearly related to the outdoor temperature in transient seasons but were discrete in the summer/winter seasons due to the mixed-mode operations of heating/cooling devices. The occupants' neutral temperatures varied with outdoor temperatures in step with seasonal changes.

Umberto et al., [7] investigate the effects of climate changes on the heating and cooling energy demand in Canada, Statistical and dynamical downscaling methods are utilized to generate several future weather files, starting from different baseline climates .In dynamical downscaling, a regional climate model is used to obtain a finer resolution than traditional general circulation models. The generated future weather data sets are then used for simulating the energy demand of 16 building prototypes. The simulation results show an average decrease of $18 \%-33 \%$ for the heating energy use intensity, and an average increase of 15\%-126\% for the cooling energy use intensity by 2070 .

Zhou et al., [8] optimiz the multi-layer perceptron (MLP) neural network with two metaheuristic algorithms, namely artificial bee colony $(A B C)$ and particle swarm optimization (PSO) for estimating the heating load $(\mathrm{HL})$ and cooling load $(\mathrm{CL})$ of the energy efficient buildings with the residential use. The results reveal that applying the $A B C$ and PSO algorithms, helps the MLP to perform more efficiently.

Zhanjun et al., [9] studied pursues optima modification of heating, ventilating, and air conditioning (HVAC) systems embedded in residential buildings through predicting heating load (HL) and cooling load $(\mathrm{CL})$, by employing four algorithms, namely winddriven optimization (WDO), whale optimization algorithm (WOA), spotted hyena optimization (SHO), and salp swarm algorithm (SSA) synthesized with a multi-layer perceptron (MLP) neural work in order to overcome the computational shortcomings of this model. Regarding the satisfying accuracy of the SSA-based ensemble, it can be a reliable tool for estimating the $\mathrm{HL}$ and $\mathrm{CL}$ for future smart city planning.

To reduce energy consumption's in building under study, a dynamic simulation are used to calculate the capacity of cooling and heating in a residential building and their relationship with internal and external temperatures through the study of two different scenarios, the first scenario without internal gain and in the second scenario internal gains are taken into consideration in order to show their effect on the thermal comfort. 
This work contributes to the quantitative understanding of the building temperature and the energy loads, which can control the residential energy management. It thus provides evidence of policy development to discourage excessive cooling and heating requirements.

This paper has assessed both thermal comfort and energy consumption for the whole building.

\section{Consumption of Electricity in Algeria}

The production of electricity in Algeria was 25.8 billion KWh in 2002 and 40,06 billion KWh in 2007 and the country consumption is between 25 and $30 \mathrm{TWh} / \mathrm{year}$. As Algeria populations grow many faster than the average $3 \%$, the need for more and more energy is exacerbated [10].

\subsection{The Consumption of Electricity in Bechar}

According to data provided by the head of Sonelgaz of Bechar Figure 1 shows that the annual electricity consumption in GWH was $613.82 \mathrm{GWh} /$ year in 2018 [11]. According to the same information source the total demand for electricity by the individual residences increases each year, sector of dwelling BDT (Buildings with the use of dwellings and trade) is the most consuming sector with $414 \mathrm{GWh}$ to maintain the occupants of the buildings in thermal comfort for the hot periods which occupy most of the year. Comparing by the $A B$ (administrative buildings) which use $52.57 \mathrm{GWh}$. On the other hand, the sector IB (industrial buildings) consumes is $147.25 \mathrm{GWh}$.

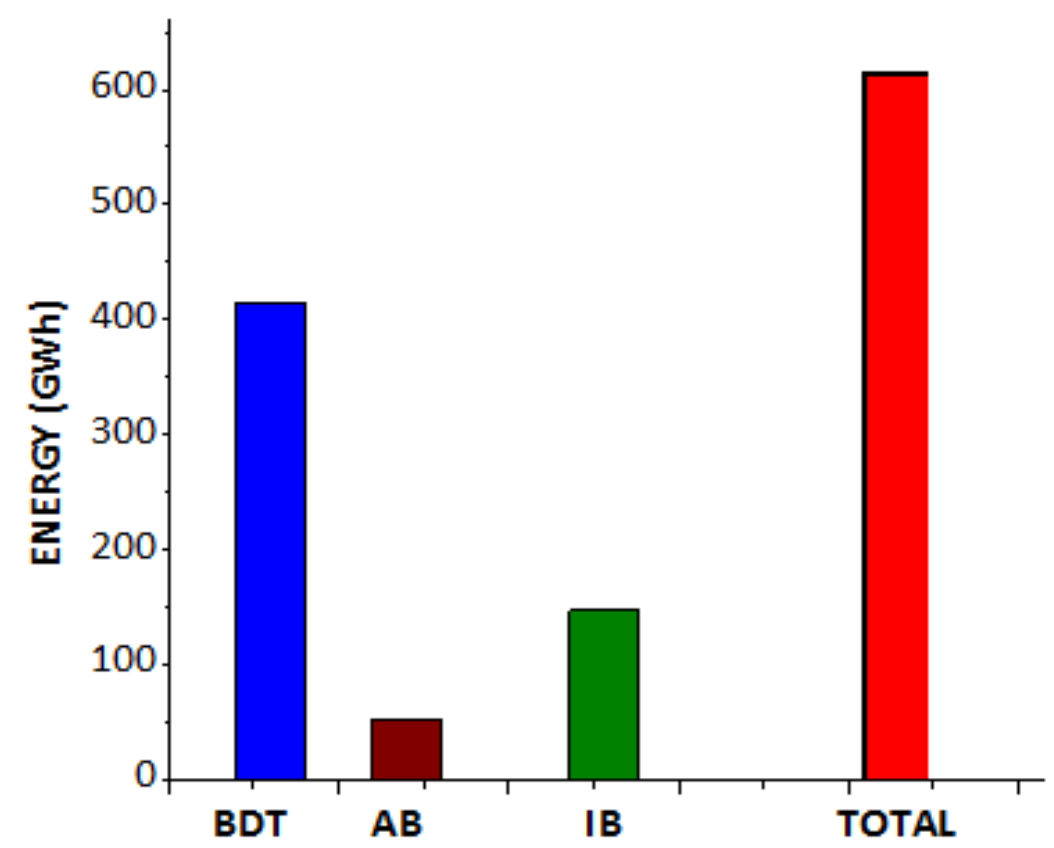

Fig. 1. Annual electric energy consumption (GWh) in Bechar, 2018

Figure 2 shows the total electricity consumption by quarters of 2018, the consumption in third quarter (July, August and September) is about $219.05 \mathrm{GWh}$, which represents twice the consumption during the first and second quarter.

Also, it was found that electricity consumption in BDT decreased from $75.60 \mathrm{GWh}$ in the first quarter to $65.75 \mathrm{GWh}$ in the second quarter, reaching its highest value of $156.98 \mathrm{GWh}$ in the third quarter [11], this electrical peak demands coincides with the period in which solar intensity is very high due to the increasing need for air conditioning in such periods. 


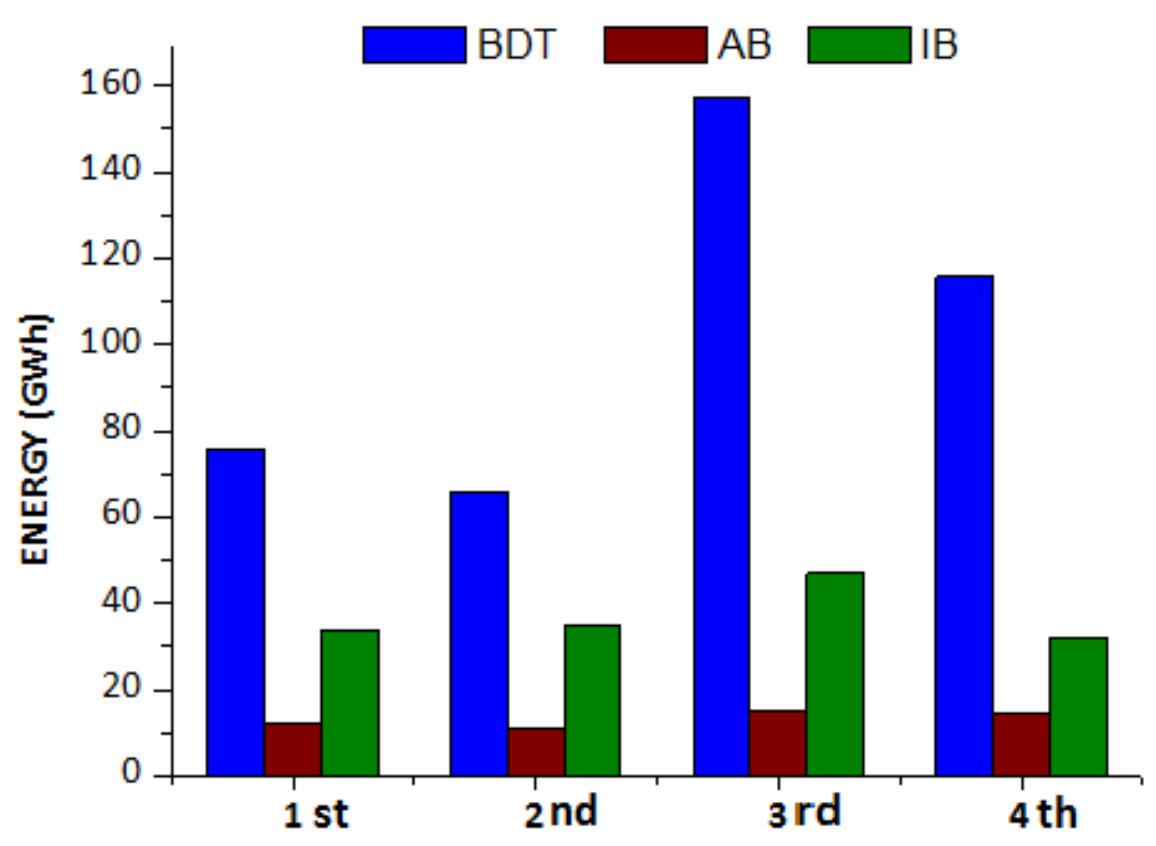

Fig. 2. Specific electricity consumption by quarters (GWh) in Bechar, 2018

\section{System Simulation}

The simulations, described in the present study, were performed using the TRNSYS simulation tool. Trnsys was originally developed at the University of Wisconsin - Madison solar energy laboratory. It was made commercialised in 1975, it consisted then of an equation solver with a few solar thermal components "Trnsys ". Since then, the program has been expanded into a comprehensive package to model buildings and energy systems. It has become a reference program for solar and other renewable energy systems and buildings [12].

\subsection{Climate and Energy Considerations in Bechar}

In many applications, such as in solar energy technologies an accurate climatic database is needed. In these applications, we consider the accuracy of solar radiation and ambient air temperature as crucial. Bechar is the largest city in southwestern Algeria [13], it is one of the sweltering cities its climate can be classified as desert heat and dryness.

The climatic based one-year concept for Bechar characterized by series of 8760 hourly outdoor data as dry bulb temperature, direct and diffuse horizontal solar radiation, wind velocity and direction, absolute and relative humidity have been used in this work. In Bechar, we distinguish two dominant seasons: hot and long period from April to September, The second season, cold and short from January to April.

The geographic coordinates of weather stations and years of measurements are presented in Table 1 [14].

Table 1

Geographical coordinates of the data collection station used in the study

\begin{tabular}{llll}
\hline Station code (AWS) & Longitude $\left({ }^{\circ}\right)$ & Latitude $\left({ }^{\circ}\right)$ & Altitude $(\mathrm{m})$ \\
\hline 605710 & -2.27 & 31.646 & 811.1 \\
\hline
\end{tabular}




\subsection{Building Description}

The house concerned under study has a $78.75 \mathrm{~m}^{2}$ floor area, divided into 5 areas (living room, kitchen, two rooms, wc and bath) and it has four external walls which are $10.5 \mathrm{~m}$ in length and $7.5 \mathrm{~m}$ in width. The house is constructed with double walls made of 10 and $15 \mathrm{~cm}$ hollow brick and plaster of $1.5 \mathrm{~cm}$ and mortier of $2 \mathrm{~cm}$ and layer of $4 \mathrm{~cm}$ insulation in between them. The average of height is about $3 \mathrm{~m}$ the convective and radiant losses and gains are calculated with Trnsys.

After selecting the zone construction, Internal energy is the heat created due to lights, equipment, presence of people and the level of their activity, as well as any other instantaneous heat gains to space.

\section{Internal Gains}

\subsection{Occupation}

Occupancy information in buildings has a great impact on energy consumption as well as indoor environment quality [15]. Many studies showed that approximately $10 \%-40 \%$ of the energy consumption in buildings can be saved with occupancy information [16].

It is considered that the building shelters four people whose sensible heat is of $71 \mathrm{~W}$ and the latent heat is of $60 \mathrm{~W}$ [17]. The metabolic level of activity is 1.5 met of 08:00 to 23:00, and 1 met of 23:00 to 08:00 With regard to the thermal resistance of clothing is equal to 0.5 clo (summer clothing), and a relative speed of air equal to $0.1 \mathrm{~m} / \mathrm{s}$. The magnitude of heat generated by occupants in the building depends on the level of activity of a person [18].

The profits of occupant's as shown in Figure 3 represents an essential component of the heat balance of a building and can contribute to the rise of the building internal temperature and thus influences the requirements in cooling and air-conditioning.

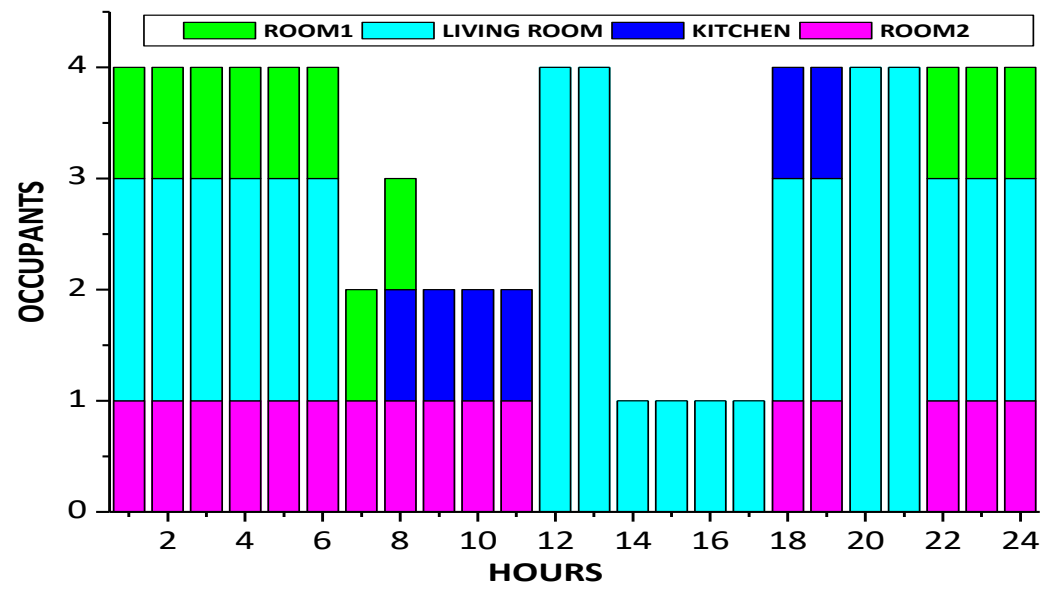

Fig. 3. Occupation's scenario of zones

\subsection{Lighting}

The lighting of the building includes fluorescent lamps of $10 \mathrm{~W}$ depending on the use of each room of the building as shown in Figure 4. 


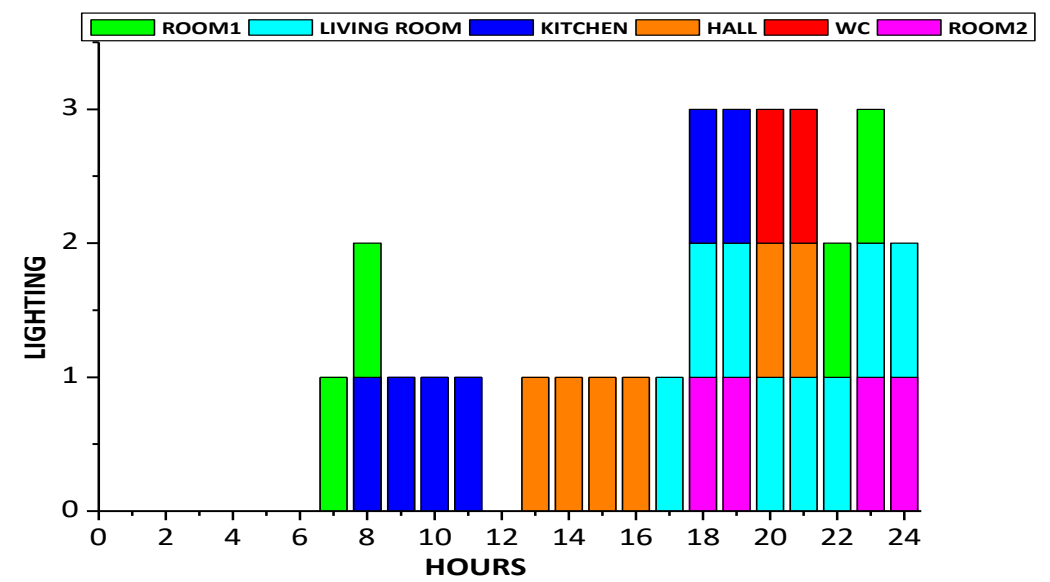

Fig. 4. Scenario of lighting of zones $\left(10 \mathrm{~W} / \mathrm{m}^{2}\right)$

\subsection{The Electric Machines}

The use of most electrical machines is related to the presence and of human activity. The apparatuses can constitute at the same time a significant and latent source of heat, or only one source of significant profits, Table 2 presented the electrical machines used in the building and their energy consumption.

\section{Table 2}

Wattage of Common Household Appliances

\begin{tabular}{llll}
\hline Machines & Zoned & Load $(\mathrm{W})$ & Schedule \\
\hline Fridge & Kitchen & 100 & $24 \mathrm{~h}$ \\
Electric cooker & Kitchen & 4500 & $10-11$ and 18-19 \\
Television & Living room & 150 & $18-21$ \\
Computer & Room & 100 & $18-19$ \\
\hline
\end{tabular}

\subsection{Scenarios}

Two scenarios are studied.

i. Scenario 1: the building without occupation and without electric machines and lighting.

ii. Scenario 2: the building with occupation, light and electric machines.

\section{Simulation}

Transient System Simulation Program TRNSYS was used to simulate the building, in order to calculate its demands in terms of cooling and heating energies. These depend on a great number of parameters, such as: size and geometrical characteristics of the building, orientation, construction materials, activity, internal sources of heating, ventilation, lighting, desired values of indoor temperature and humidity, during summer and winter meteorological conditions [19]. The simulation of multi-zonal buildings passes by several stages.

i. Collection of the required meteorological data of the examined area, the data are those of the solar radiation, the relative humidity and both strength and direction of wind. The weather values of a Typical Meteonorm Year (TMY) were obtained through the (Meteonorm) software program. In the cooling mode the set point temperature is fixed to $26^{\circ} \mathrm{C}$ for all building zones, in the heating mode, the set point temperature is set to $18^{\circ} \mathrm{C}$. 
ii. Separate the unit from the house in various zones coupled the ones with the others. Then the description of the envelope of the building, the windows, the internal profit. Type 56 makes it possible to obtain this information and to generate the input files necessary for a simulation with TRNSYS.

iii. Study of the maximum, minimum and average heating and cooling energy needs of the building, to maintain stable humidity and temperature conditions within the building, the heating and cooling loads should be calculated. Figure 5 shows a graphical interface of the modeling worked out under TRNSYS.

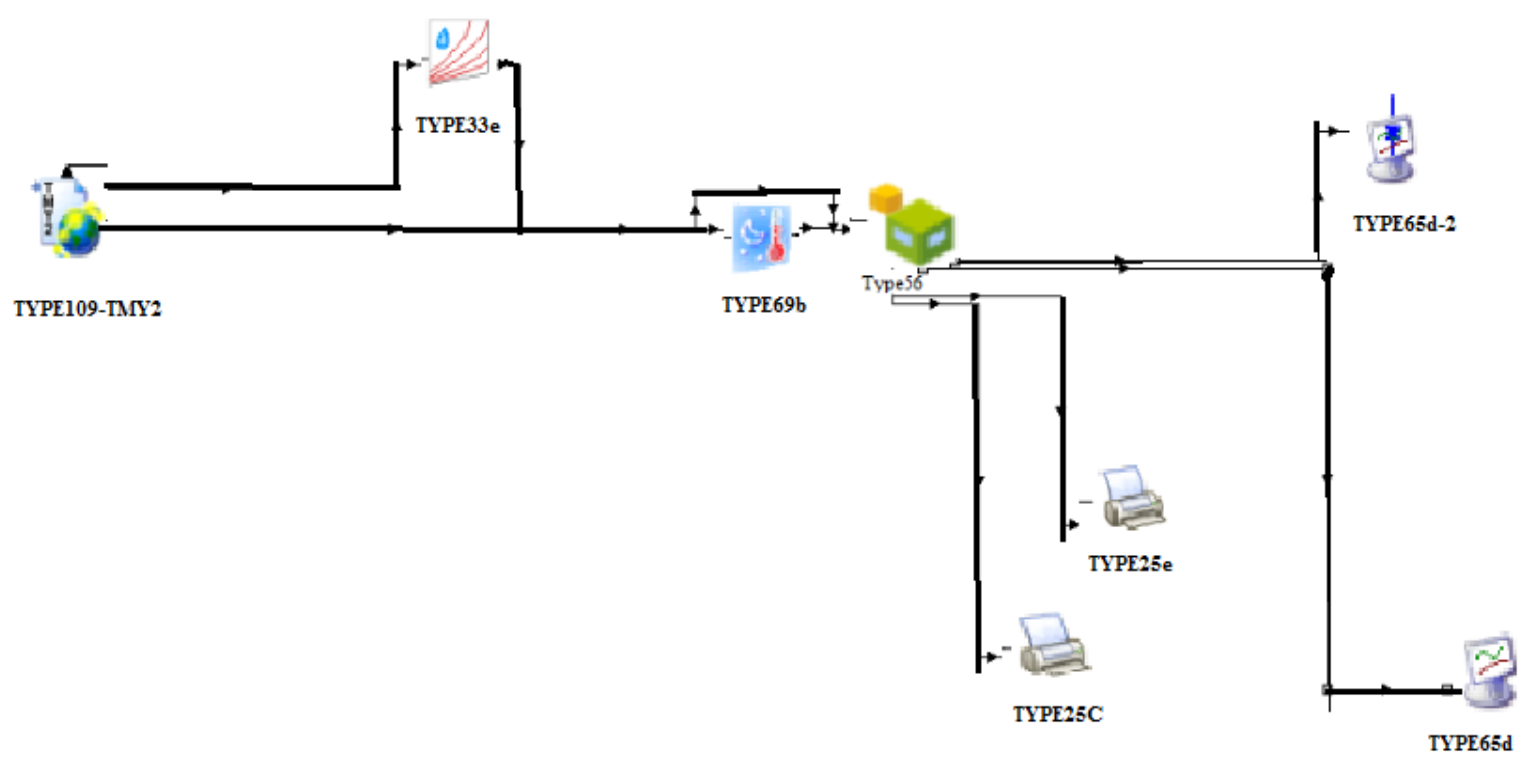

Fig. 5. Representation of the subsystem building in the interface of TRNSYS

\section{Results and Discussions}

\subsection{The Temperature}

Thermal comfort effect has been measured in term of the number of discomfort hours [20], by measure of the temperatures in each zone using TRNSYS.

Figure 6 represents the free evolution of the average ambient temperature (TAMB) profile and the average internal temperatures with degree Celsius in the four zones during one year in the first scenario (without internal gains).

The data represented previously shows that all the months of the year are situated in discomfort zone except months of March, April and October and the average internal temperature is always higher than the average ambient temperature. The Internal temperatures from May to September are too high $\left(\mathrm{T}>26^{\circ} \mathrm{C}\right)$ the maximum is registered in July (living room) with values of $36.15^{\circ} \mathrm{C}$ and the maximum of ambient temperature is $33.08^{\circ} \mathrm{C}$.

In the months: January, February, November and December, the discomfort in the various rooms increases due to the decrease in the solar gains and consequently the internal temperatures decrease. The low temperature was registered in January at $11.86^{\circ} \mathrm{C}$ (the living room). 


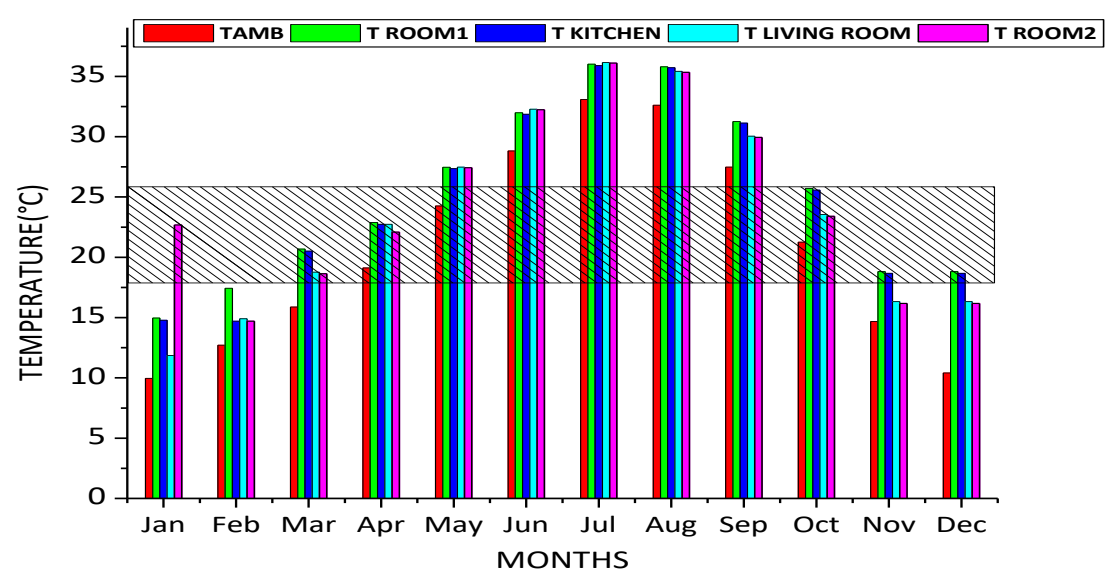

Fig. 6. Evolution of the internal temperatures (1st Scenario)

Figure 7 gives a closer look of internal temperatures profile in the second scenario (with internal gains). It is noticed that the months: March, April and some zones in October and November are located in the comfort area (grid zone), and this is due to the increase of the internal temperature because the presence of internal gains in these zones and therefore reducing of heating loads.

From May to October, the internal temperatures in this scenario are higher than the temperatures in the first scenario and the demand for cooling increases.

The maximum temperature was registered during the July month in the kitchen at $38.03^{\circ} \mathrm{C}$ due to the use of electrical machines, and the minimum in the second room with a value of $12.80^{\circ} \mathrm{C}$ in December month.

The Internal gains effect on internal temperatures and result in an impact on energy consumption, so it is important to evaluate the cooling and Heating required for the building to achieve the optimum thermal comfort especially in the area outside the comfort zone $\left(18^{\circ} \mathrm{C}\right.$ $<\mathrm{T}<26^{\circ} \mathrm{C}$ )

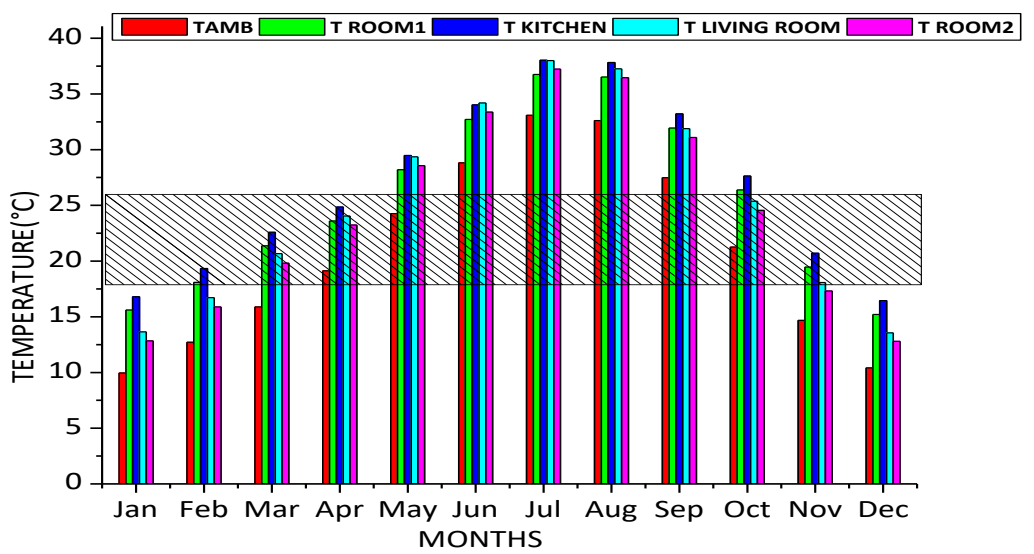

Fig. 7. Evolution of the internal temperatures (2nd Scenario)

\subsection{Energy of Cooling and Heating}

The required energy for cooling and heating was calculated according to the outputs of Trnsys. In the first scenario, it is noted that the loads of cooling are higher than the loads of heating and required in a long time of the years. It is obvious that the annual required energy of cooling is 10.813,3 KWh per year and the annual required energy of heating is $6.511,90 \mathrm{KWh}$ per year. The needs for cooling present $62.41 \%$ and of heating present $37.59 \%$. 
The need for air conditioning reaches its peak in July with a maximum value of $2206 \mathrm{KWh}$, the peak heating demand is $1568 \mathrm{KWh}$ is in the month of January as shown in Figure 8 below.

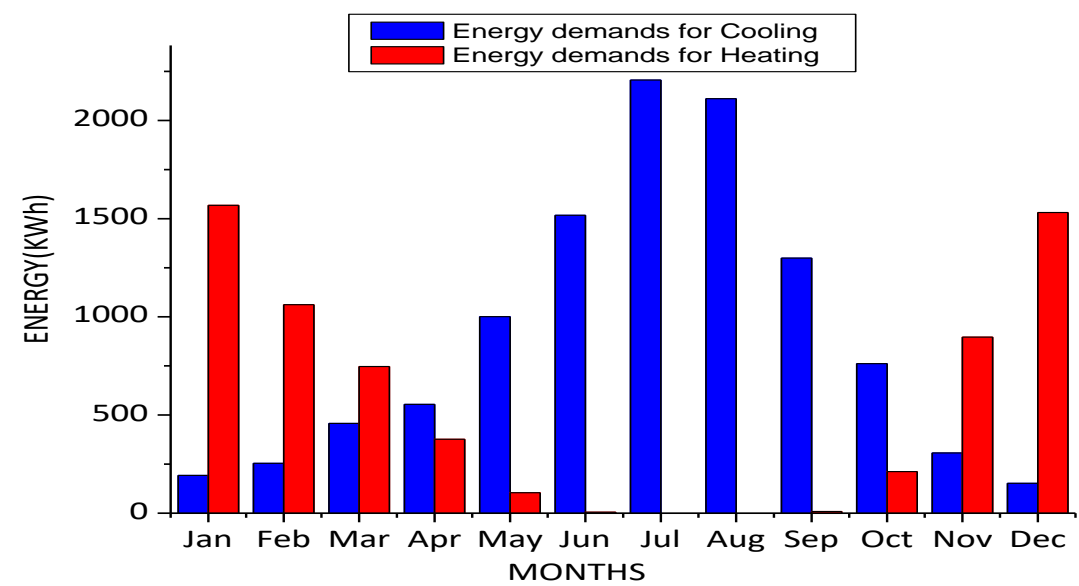

Fig. 8. Heating and cooling energy on monthly base (1st scenario)

Figure 9 presents the energy consumption for cooling during one-year period as for heating in second scenario. The peak of energy demands as these were calculated in Trnsys, we have found that an annual base, the load of cooling is $12.223,30 \mathrm{KWh}$ which represented with $69.51 \%$ and for heating with $5.361,30 \mathrm{KWh}$ present $30.49 \%$ per year.

The heating requirements have a peak in January and December with values of $1337 \mathrm{KWh}$ and $1302 \mathrm{KWh}$ respectively. And the cooling needs increase gradually to the maximum in July with a value of $2361 \mathrm{KWh}$ and in August with $2269 \mathrm{KWh}$.

The energy consumption profile is quite similar to internal temperature profile, the peak of cooling corresponds clearly to the highest temperatures.

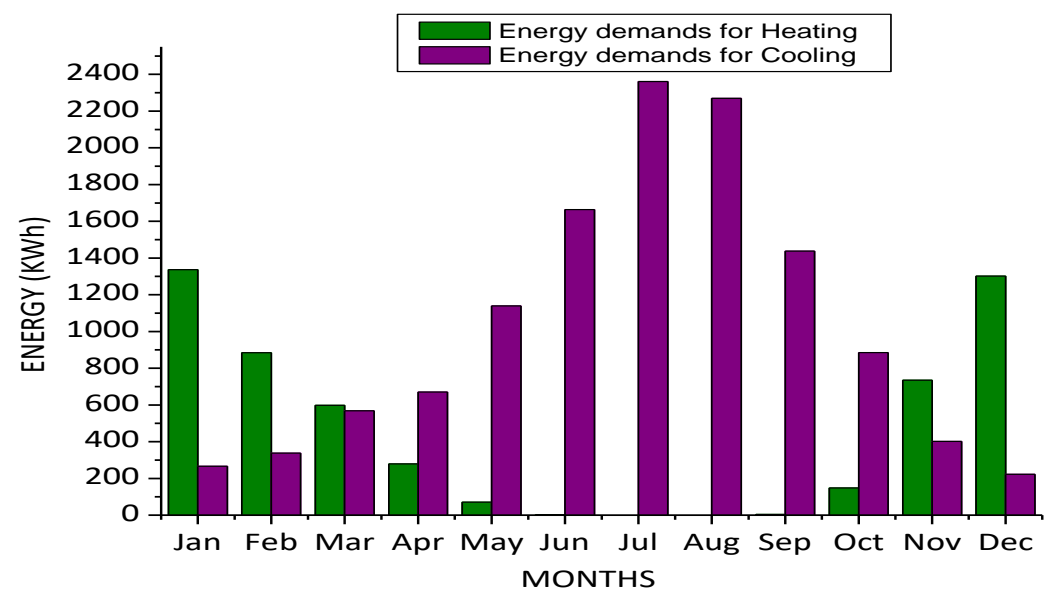

Fig. 9. Heating and cooling energy on monthly base (2nd scenario)

Figure 10 shows the results of thermal loads for cooling obtained by TRNSYS during one-year period in two scenarios with and without gains.

First scenario without gains: The curves can be divided into three periods.

i. Period 1: from month 1 to month 4: this period corresponds to the cold season, where cooling is not required.

ii. Period 2: 5th month to 9th month: This period corresponds to the hot season, cooling needs increase to reach its maximum in the month of July. 
iii. Period 3: from the 10th month to the 12th month: cooling loads decrease sharply from 761.80 $\mathrm{KWh}$ in October to $152.50 \mathrm{KWh}$ in December.

Second scenario with gains: The curves can be divided into two periods.

i. Period 1: from 1 month to 8th month: the cooling loads increase from January with a 266.2 KWh until July and August.

ii. Period 2: from the 9th month to the 12th month: the cooling needs decrease to reach their minimum in December with a value of $222.7 \mathrm{KWh}$.

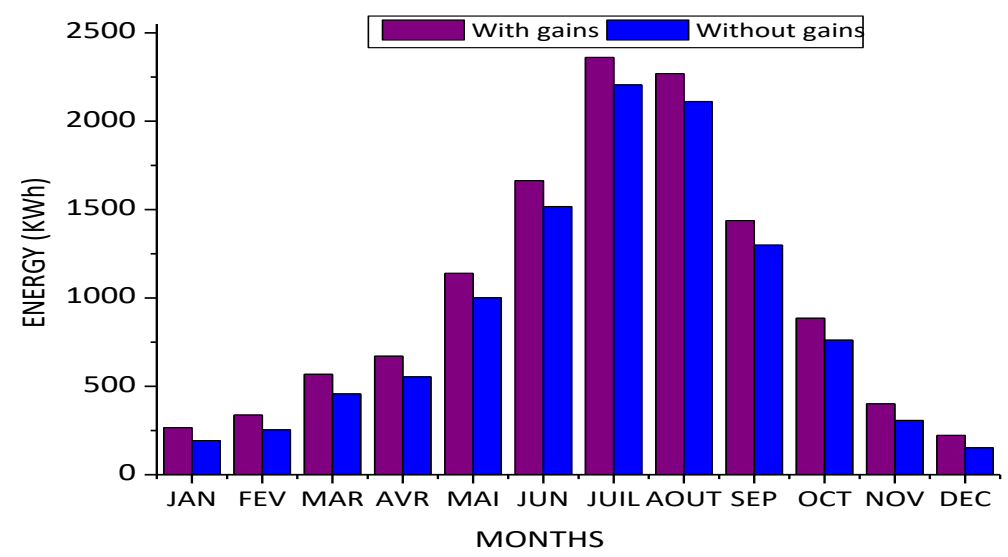

Fig. 10. Thermal loads for cooling

Figure 11 shows the heating needs for a year on the based on a set temperature of $18^{\circ} \mathrm{C}$, if the internal contributions are neglected and if included.

The heating needs for a year, if the internal contributions are neglected, is $6511.90 \mathrm{KWh}$. But when included in calculation, it is $5361.30 \mathrm{KWh}$.

So, the internal contributions in the habitat clearly decrease the demand for heating and reaches at almost $10 \%$.

Without internal input, the heating demand reaches maximum of $1568 \mathrm{KWh}$ in January and 1531 $\mathrm{KWh}$ in December, the heating demand is reduced until becomes zero in June, July and August. For the calculation of the real demand we must include the use rate of the internal contributions that are represented in the figures.

With internal supplies, the heating demand decreases by $231 \mathrm{KWh}$ in January. This will save energy worth $229 \mathrm{KWh}$ for the month of December.

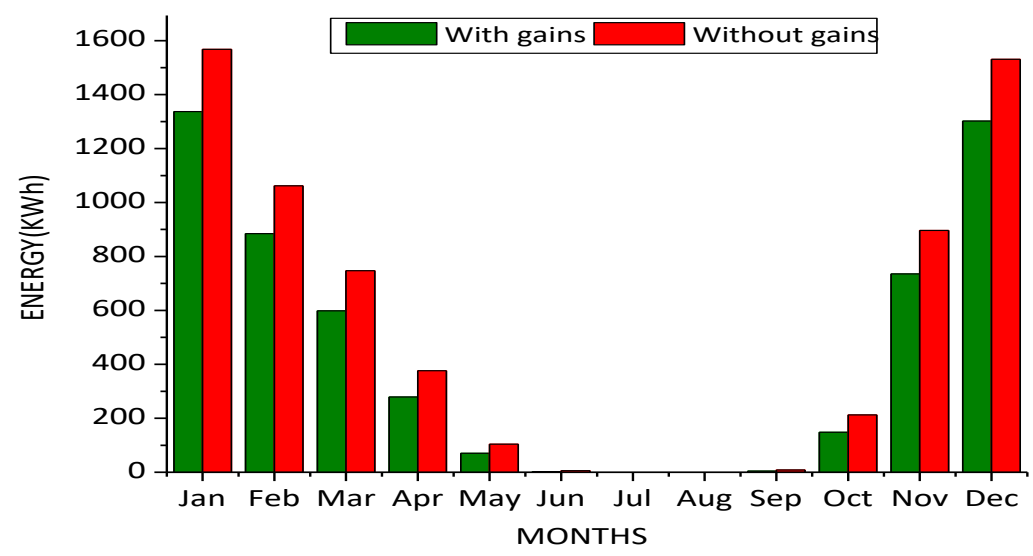

Fig. 11. Heating energy on monthly base 


\section{Conclusion}

In this study the heating and cooling energy consumptions for house located in Bechar are determined using Trnsys software for one year. The simulation results including internal gains and their associated heating and cooling loads with an emphasis on the results for the residential buildings in Bechar has been presented.

We observe that where the internal gain are taken into consideration, the demand for cold is quite important, without the internal gains the demand for cold is $62.41 \%$ whereas in real cases, with the internal contributions that influence in thermal comfort, demand is $69.51 \%$.

The temperature is an important component in this study, temperature can provide a high expectation of thermal comfort of occupant in the building, it increase with the internal gains, the most important values of gap registered a temperature difference more than $1.8^{\circ} \mathrm{C}$, but saves up to $6 \%$ cooling energy.

Internal supplies therefore have a strong impact on energy consumption, the use of internal supplies factor is used to calculate net demand for air conditioning.

i. The received heat input clearly reduces the heating demand by almost $10 \%$ in winter.

ii. The role of the internal gains is the creation of thermal comfort and regulation of indoor temperatures in winter, but it has an impact on energy consumption in summer because of the use of air conditioning which will serve to keep up an acceptable temperature.

iii. The climate of Bechar characterised by a hotter season longer than the cold one, the consumption of cooling energy is as important as more than twice the consumption of heating energy in the year. The most interesting is that the demand for cold varies depending upon the sunshine, so using this energy source for air conditioning, and home cooling systems would be of a great wisdom.

The study of the temperature and the cooling and heating loads helps designers and building owners to economically reduce building operating costs, while improving the indoor thermal comfort for the building's occupants. Furthermore, thermal comfort plays a major role in buildings sector, especially in hot-arid climate.

\section{References}

[1] Fan, Yuling, and Xiaohua Xia. "A multi-objective optimization model for building envelope retrofit planning." Energy Procedia 75 (2015): 1299-1304.

https://doi.org/10.1016/i.egypro.2015.07.193

[2] Fezzioui, Naïma, Draoui Belkacem, Benyamine Mebirika and Salah Larbi. "Influence of Dynamic Characteristics of the Building Envelope on Thermal Comfort in Southern Algeria (in French)." Revue des Energies Renouvelables 11, no. 1 (2008): 25-34.

[3] Nadia, Nait, Fatiha Bourbia, and Yasmina Bouchahm. "Effect of thermal insulation on energy efficiency of the building envelope-semi dry climates." In Advances on Sustainable Cities and Building Development Conference, Sb - Lab (2017).

[4] Chaowen, $\mathrm{Hu}$, and Wei Dong. "Prediction on hourly cooling load of buildings based on neural networks." International Journal of Smart Home 9, no. 2 (2015): 35-52. https://doi.org/10.14257/ijsh.2015.9.2.04

[5] Vallejo-Coral, E. Catalina, C. I. Rivera-Solorio, M. Gijón-Rivera, and Hugo F. Zúñiga-Puebla. "Theoretical and experimental development of cooling load temperature difference factors to calculate cooling loads for buildings in warm climates." Applied Thermal Engineering 150 (2019): 576-590.

https://doi.org/10.1016/i.applthermaleng.2018.12.136

[6] Du, Chenqiu, Baizhan Li, Wei Yu, Hong Liu, and Runming Yao. "Energy flexibility for heating and cooling based on seasonal occupant thermal adaptation in mixed-mode residential buildings." Energy 189 (2019): 116339. https://doi.org/10.1016/i.energy.2019.116339

[7] Berardi, Umberto, and Pouriya Jafarpur. "Assessing the impact of climate change on building heating and cooling energy demand in Canada." Renewable and Sustainable Energy Reviews 121 (2020): 109681. 
https://doi.org/10.1016/j.rser.2019.109681

[8] Zhou, Guofeng, Hossein Moayedi, Mehdi Bahiraei, and Zongjie Lyu. "Employing artificial bee colony and particle swarm techniques for optimizing a neural network in prediction of heating and cooling loads of residential buildings." Journal of Cleaner Production 254 (2020): 120082.

https://doi.org/10.1016/i.jclepro.2020.120082

[9] Guo, Zhanjun, Hossein Moayedi, Loke Kok Foong, and Mehdi Bahiraei. "Optimal modification of heating, ventilation, and air conditioning system performances in residential buildings using the integration of metaheuristic optimization and neural computing." Energy and Buildings 214 (2020): 109866.

https://doi.org/10.1016/i.enbuild.2020.109866

[10] Stambouli, Amine Boudghene. "Promotion of renewable energies in Algeria: strategies and perspectives." Renewable and Sustainable Energy Reviews 15, no. 2 (2011): 1169-1181.

https://doi.org/10.1016/i.rser.2010.11.017

[11] Bechar. State-owned utility in charge of electricity and natural gas distribution in Algeria (Sonalgaz). Data and Indicators, 2018.

[12] S. A., Klein, Duffie, J. A., Mitchell, J. C., Kummer J. P., Beckmann, W. A., and Duffie, N.A. TRNSYS - A Transient Simulation Program. Users Manual, 1994.

[13] Mohammed, Madi, Mohammed Amin Hafnaoui, Ali Hachemi, Mosbah Ben Said, Abderrahmane Noui, Abdelhalim Mghezzi Chaa, Nora Bouchahm, Yacine Farhi. "Flood risk assessment in Saharan regions. A case study (Bechar region, Algeria)." Journal of Biodiversity and Environmental Sciences 16, no. 1 (2020): 42-60.

[14] Abderrahim, Asma, Nassera Ghellai, Zakaria Bouzid, and Younes Menni. "Wind Energy Resource Assessment in South Western of Algeria Wind Energy Resource Assessment in South Western of Algeria." Mathematical Modelling of Engineering Problems 6, no. 2 (2019): 157-162.

https://doi.org/10.18280/mmep.060201

[15] Yang, Junjing, Mattheos Santamouris, and Siew Eang Lee. "Review of occupancy sensing systems and occupancy modeling methodologies for the application in institutional buildings." Energy and Buildings 121 (2016): 344-349. https://doi.org/10.1016/i.enbuild.2015.12.019

[16] Sun, Kailai, Qianchuan Zhao, and Jianhong Zou. "A review of building occupancy measurement systems." Energy and Buildings (2020): 109965.

https://doi.org/10.1016/j.enbuild.2020.109965

[17] CNIRIB. "Technical Document C 3-4: Rules of calculation of the calorific contributions." Air-conditioning, 1998.

[18] Kumar, Rajesh, R. K. Aggarwal, J. D. Sharma, and Sunil Pathania. "Predicting energy requirement for cooling the building using artificial neural network." Journal of Environmental Engineering And Technology 2, no. 1 (2013): 2165-8315.

[19] Tsoutsos, Th, E. Aloumpi, Z. Gkouskos, and M. Karagiorgas. "Design of a solar absorption cooling system in a Greek hospital." Energy and Buildings 42, no. 2 (2010): 265-272.

https://doi.org/10.1016/i.enbuild.2009.09.002

[20] Morsy, M., M. Fahmy, H. Abd Elshakour, and A. M. Belal. "Effect of Thermal Insulation on Building Thermal Comfort and Energy Consumption in Egypt." Journal of Advanced Research in Applied Mechanics 43, no. 1 (2018): 8-19. 